\title{
Elevated Membrane Cholesterol Disrupts Lysosomal Degradation to Induce $\beta$-Amyloid Accumulation
}

\section{The Potential Mechanism Underlying Augmentation of $\beta$-Amyloid Pathology by Type 2 Diabetes Mellitus}

\author{
Shingo Takeuchi, ${ }^{*}$ Naoya Ueda, ${ }^{*}$ Keiko Suzuki, ${ }^{*}$ Nobuhiro Shimozawa, ${ }^{\dagger}$ Yasuhiro Yasutomi, ${ }^{\dagger}$ and Nobuyuki Kimura*
}

From the Section of Cell Biology and Pathology, * Department of Alzheimer's Disease Research, Center for Development of Advanced Medicine for Dementia, National Center for Geriatrics and Gerontology, Obu; and the Tsukuba Primate Research Center, ${ }^{\dagger}$ National Institutes of Biomedical Innovation, Health and Nutrition, Tsukuba, Japan

\author{
Accepted for publication \\ October 4, 2018. \\ Address correspondence to \\ Nobuyuki Kimura, D.V.M., \\ Ph.D., Section of Cell Biology \\ and Pathology, Department of \\ Alzheimer's Disease Research, \\ Center for Development of \\ Advanced Medicine for De- \\ mentia, National Center for \\ Geriatrics and Gerontology, \\ Morioka 7-430, Obu, Aichi \\ 474-8511, Japan. E-mail: \\ kimura@ncgg.go.jp.
}

\begin{abstract}
The endocytic membrane trafficking system is altered in the brains of early-stage Alzheimer disease $(A D)$ patients, and endocytic disturbance affects the metabolism of $\beta$-amyloid $(A \beta)$ protein, a key molecule in $A D$ pathogenesis. It is widely accepted that type 2 diabetes mellitus (T2DM) is one of the strongest risk factors for development of AD. Supporting this link, experimentally induced T2DM enhances AD pathology in various animal models. Spontaneous T2DM also enhances A $\beta$ pathology with severe endocytic pathology, even in nonhuman primate brains. However, it remains unclear how T2DM accelerates $A \beta$ pathology. Herein, we demonstrate that cholesterol metabolism-related protein levels are increased and that membrane cholesterol level is elevated in spontaneous T2DM-affected cynomolgus monkey brains. Moreover, in vitro studies that manipulate cellular cholesterol reveal that elevated membrane cholesterol disrupts lysosomal degradation and enhances chemical-induced endocytic disturbance, resulting in great accumulation of $A \beta$ in Neuro2a cells. These findings suggest that an alteration of cerebral cholesterol metabolism may be responsible for augmentation of $A \beta$ pathology in T2DM-affected brains, which, in turn, may increase the risk for developing AD. (Am J Pathol 2019, 189: 391-404; https://doi.org/10.1016/j.ajpath.2018.10.011)
\end{abstract}

\begin{abstract}
Alzheimer disease $(\mathrm{AD})$ is a progressive neurodegenerative disorder that is histopathologically characterized by the formation of senile plaques and neurofibrillary tangles. ${ }^{1,2}$ It is widely accepted that $\beta$-amyloid (A $\beta$ ), the major component of senile plaques, is a key molecule in AD pathogenesis. ${ }^{3,4} \mathrm{~A} \beta$ is produced by sequential cleavage of $\beta$-amyloid precursor protein (APP) in the endocytic pathway. ${ }^{5-7}$ In the brains of patients with early-stage $\mathrm{AD}$, endocytic pathology is manifested as intracellular accumulation of abnormally enlarged endosomes. Intracellular accumulation of APP and A $\beta$ is commonly observed in such enlarged endosomes, suggesting that the endocytic membrane trafficking system is altered in the brain of $\mathrm{AD}$ patients. ${ }^{8-11}$
\end{abstract}

Our previous studies showed that interaction of the microtubule-based motor protein dynein with dynactin is attenuated in the brains of aged cynomolgus monkeys (Macaca fascicularis), suggesting that the dynein-mediated transport is disrupted in aged brain. ${ }^{12}$ Endocytic pathology occurs in the brains of aged cynomolgus monkeys, and

\footnotetext{
Supported in part by National Center for Geriatrics and Gerontology Research Funding for Longevity Sciences grants 28-27 (N.K.) and 28-37 (N.K.), the Japan Agency for Medical Research and Development grant JP18ak0101047h0003 (N.K.), and the Japan Society for the Promotion of Science grant-in-aid for scientific research (B) JP17H03574 (N.K.).

Disclosures: None declared.
} 
dynein dysfunction reproduces endocytic pathology, resulting in the intracellular accumulation of $\mathrm{A} \beta .^{13}$ Moreover, recent genome-wide association studies have revealed that several variants of the endocytosis-related gene are associated with $\mathrm{AD},{ }^{14-18}$ and the studies using Fluorlabeled ligands demonstrated that endocytosis mediates the internalization of extracellular $A \beta$ in neurons. ${ }^{19,20}$ These findings suggest that alterations in the endocytic membrane trafficking system are involved in AD pathogenesis. Even with all this evidence, it remains unclear why endocytic disturbance is enhanced in AD patient brains.

Several epidemiologic and clinical studies showed that type 2 diabetes mellitus (T2DM) patients have high susceptibility to AD in their later life. ${ }^{21-26}$ Moreover, experimental induction of T2DM enhances $\mathrm{AD}$ pathology in various animal models. ${ }^{27}$ Spontaneous T2DM enhances A $\beta$ pathology even in nonhuman primate brains, and severe endocytic pathology is also observed in T2DM-affected monkey brains. ${ }^{28}$ However, it remains unclear how T2DM accelerates $A \beta$ pathology. Thus, we hypothesized that T2DM may alter the endocytic membrane trafficking system in a way that enhances endocytic disturbance.

Herein, we demonstrate that cholesterol metabolism-related protein levels are increased and that the membrane cholesterol level is elevated in the brains of spontaneous T2DM-affected monkeys. Moreover, in vitro studies by using methyl$\beta$-cyclodextrin $(\mathrm{M} \beta \mathrm{CD})$-cholesterol reveal that elevated membrane cholesterol disrupts lysosomal degradation and enhances chloroquine- and ciliobrevin $\mathrm{D}$-induced endocytic disturbance, resulting in great accumulation of $A \beta$ in Neuro2a cells. These findings suggest that an alteration in cerebral cholesterol metabolism may be responsible for the severe endocytic disturbance in T2DM-affected brains, which, in turn, may increase the risk for developing $\mathrm{AD}$ accompanied by augmentation of $A \beta$ pathology.

\section{Materials and Methods}

\section{Antibodies}

For Western blot analyses, the following primary antibodies were used: rabbit polyclonal anti-Akt antibody (1:5000; Cell Signaling Technology, Danvers, MA; catalog number 9272); rabbit monoclonal anti-phosphorylated Akt antibody (1:5000; Cell Signaling Technology; 4060); rabbit monoclonal antiGSK3 $\beta$ antibody (1:10,000; Cell Signaling Technology; 12,456); rabbit monoclonal anti-phosphorylated GSK3 $\beta$ antibody (1:10,000; Cell Signaling Technology; 5558); mouse monoclonal anti- $\beta$-actin antibody (1:200,000; Sigma, St. Louis, MO; A5441); rabbit polyclonal anti-sterol regulatory element-binding protein 2 (SREBP2) antibody (1:5000; Cayman Chemical, Ann Arbor, MI; 10007663); goat polyclonal anti-apolipoprotein E (ApoE) antibody (1:5000; Millipore, Temecula, CA; AB947); rabbit polyclonal anti-ATP-binding cassette subfamily A member 1 antibody (1:2000; Abcam, Cambridge, UK; ab7360); goat polyclonal anti-low-density lipoprotein receptor-related protein 1 antibody (1:2000; Santa Cruz Biotechnology, Dallas, TX; sc-16168); rabbit monoclonal anti-APP antibody (1:10,000; Abcam; ab32136); rabbit monoclonal anti-Rab5 antibody (1:10,000; Cell Signaling Technology; 3547); rabbit polyclonal anti-Rab7 antibody (1:6000; Sigma; R4779); mouse monoclonal anti-glyceraldehyde-3phosphate dehydrogenase antibody (1:200,000; GeneTex, Irvine, CA; GTX28245); rabbit polyclonal anti-SQSTM1/p62 antibody (1:2000; Cell Signaling Technology; 5114); mouse monoclonal anti-light chain 3 (LC3) antibody (1:2000; Nanotools, Teningen, Germany; 0231-100/LC3-5F10); mouse monoclonal anti-APP clone 22C11 (1:4000; Millipore; MAB348); rabbit polyclonal anti-sAPP- $\beta$ (1:4000; BioLegend, San Diego, CA; 813401); rabbit polyclonal anti-clathrin heavy chain antibody (1:2000; Santa Cruz Biotechnology; sc-9069); and rabbit polyclonal anti-dynamin antibody (1:2000; Santa Cruz Biotechnology; sc-11362).

For immunocytochemistry, the following primary antibodies were used: rabbit polyclonal anti-APP antibody (1:2000; IBL, Gunma, Japan; 28,053); mouse monoclonal anti-Rab5 antibody (1:200; Santa Cruz Biotechnology; sc-46692); mouse monoclonal anti-Rab7 antibody (1:4000; Abcam; ab50533); mouse monoclonal anti-clathrin heavy chain (1:500; Santa Cruz Biotechnology; sc-12734); and rabbit polyclonal anti-dynamin antibody (1:1000; Santa Cruz Biotechnology; sc-11362).

\section{Animals}

Fourteen cynomolgus monkey (M. fascicularis) brains were used in this study. Of these, seven brains were from normal monkeys [age: 18 years $(n=1), 19$ years $(n=1), 20$ years $(n=2), 22$ years $(n=1), 26$ years $(n=1)$, and 28 years $(n=1)]$; and seven were from spontaneous T2DM-affected moneys [age: 18 years $(n=1), 19$ years $(n=1), 20$ years $(n=1), 21$ years $(n=2), 26$ years $(n=1)$, and 27 years $(n=1)]$. Both sexes were used. Information of all monkeys used for this study is shown in Table 1.

The cerebral cortices of 6 of the 14 monkeys were used for Western blot analyses. Of these six, three were from normal monkeys [age: 18, 19, and 20 years $(n=1$ each)]; three were from spontaneous T2DM-affected monkeys [age: 18,19 , and 20 years $(n=1$ each)]. The cerebral cortices of 8 of the 14 monkeys were used for analysis of membrane cholesterol levels. Of these eight, four were from normal monkeys [age: $20,22,26$, and 28 years $(n=1$ each)]; four were from spontaneous T2DM-affected monkeys [age: 21 years $(n=2), 26$ years $(n=1)$, and 27 years $(n=1)]$.

All brains were obtained from the Tsukuba Primate Research Center (TPRC), National Institutes of Biomedical Innovation, Health, and Nutrition (Osaka, Japan). The maintenance and care of animals were performed according to the rules for animal care of the TPRC at the National Institutes of Biomedical Innovation, Health, and Nutrition for the care, use, and biohazard countermeasure of laboratory animals. All monkeys were bred and maintained in an air- 
Table 1 Cynomolgus Monkeys Used in the Present Study

\begin{tabular}{|c|c|c|c|c|c|}
\hline Number & Age, years & Sex & Glu, mg/dL* & $\mathrm{TG}, \mathrm{mg} / \mathrm{dL}^{*}$ & Experimental purpose \\
\hline \multicolumn{6}{|l|}{ Control } \\
\hline 1 & 18 & Female & 47 & 8 & WB \\
\hline 3 & 20 & Female & 46 & 63 & WB \\
\hline 4 & 20 & Female & 34 & 47 & MC \\
\hline 5 & 22 & Male & 56 & 76 & $M C$ \\
\hline \multicolumn{6}{|l|}{ T2DM } \\
\hline 1 & 18 & Female & 154 & 766 & WB \\
\hline 2 & 19 & Female & 443 & 937 & WB \\
\hline 3 & 20 & Female & 341 & 425 & WB \\
\hline 4 & 21 & Female & 147 & 131 & MC \\
\hline
\end{tabular}

*The last value taken from each monkey.

Glu, blood glucose levels; MC, analysis of membrane cholesterol; TG, blood triglyceride levels; WB, Western blot analysis.

conditioned room at the TPRC with controlled illumination (12 hours light $/ 12$ hours dark), temperature $\left(23^{\circ} \mathrm{C}\right.$ to $\left.27^{\circ} \mathrm{C}\right)$, humidity (50\% to $70 \%$ ), and ventilation (12 air changes/ hour). Each monkey was given $70 \mathrm{~g}$ of commercially available pellet monkey chow (CMK-2; CLEA Japan, Inc., Tokyo, Japan); $100 \mathrm{~g}$ of apples; and unlimited access to tap water every day. Every morning, their health status (eg, assessment of viability, appetite, and coat appearance) was monitored. When any abnormality was found, a veterinarian examined the monkey promptly and applied the appropriate treatment, such as fluid replacement.

In the TPRC colony, some adult monkeys are spontaneously affected with T2DM for various reasons, such as pregnancy history and environmental factors. The TPRC has accumulated clinical data for $>40$ years. On the basis of these data, the normal blood glucose level for female monkeys is in the range of 24 to $74 \mathrm{mg} / \mathrm{dL}$; and for male monkeys, the range is from 24 to $76 \mathrm{mg} / \mathrm{dL}$. Normal blood triglyceride levels are in the range of 8 to $85 \mathrm{mg} / \mathrm{dL}$ for females and of 6 to $52 \mathrm{mg} / \mathrm{dL}$ for males. The animals were diagnosed with T2DM by periodic health examination, and the blood glucose and triglyceride levels of monkeys are used to outline DM criteria for this study (Table 1 and Supplemental Figure S1). T2DM-affected monkeys used in this study have not received any DM-related treatments before experiments.

This study was performed in strict accordance with the rules for animal care and management of the TPRC, ${ }^{29}$ the Guiding Principles for Animal Experiments Using Nonhuman Primates formulated by the Primate Society of Japan, ${ }^{30}$ and the Institute for Laboratory Animal Research Guide for Care and Use of Laboratory Animals. The research protocol was approved by the Animal Care and Use Committee of the National Institutes of Biomedical Innovation, Health, and Nutrition (DS17-001R1). When a monkey presented clinical symptoms due to injury or illness, and it was not expected to recover from pain or morbidity, it was judged to have a poor prognosis. The animals used in this study either died of natural causes or were euthanized when they reached end points determined as poor prognosis. For euthanasia, the monkeys were deeply anesthetized with a lethal dose of pentobarbital, and all efforts were made to minimize suffering.

\section{Biochemical Analysis of Monkey Brains}

For Western blot analyses, frozen monkey brain tissue was homogenized in a glass homogenizer with homogenate buffer solution containing $0.32 \mathrm{~mol} / \mathrm{L}$ sucrose, $10 \mathrm{mmol} / \mathrm{L}$ Tris-HCL (pH 7.6), $1 \mathrm{mmol} / \mathrm{L}$ EDTA, and cOmpleteMini proteinase inhibitor cocktail (Roche Molecular Biochemicals, Penzberg, Germany), and then the tissue was centrifuged at $1000 \times g$ for 10 minutes to obtain the supernatant fraction. The supernatant was centrifuged at $100,000 \times g$ for 1 hour to obtain the pellet fraction. The resulting pellets were resuspended in homogenization buffer and then subjected to Western blot analyses. The proteins were adjusted to $10 \mu \mathrm{g}$ and then subjected to SDS-PAGE by using $12.8 \%$ acrylamide gels. Separated proteins were blotted onto polyvinylidene fluoride membranes (Millipore). The membranes were blocked with 5\% nonfat dried milk in phosphate-buffered saline ( $\mathrm{pH} 7.0)$ and $0.1 \%$ Tween-20 for 1 hour at room temperature and then incubated with primary antibodies overnight at $4{ }^{\circ} \mathrm{C}$. They were then incubated with either horseradish peroxidase-conjugated goat anti-mouse $\operatorname{IgG}(1: 10,000)$ or goat anti-rabbit $\operatorname{IgG}(1: 10,000$; Cell Signaling Technology) for 1 hour at room temperature. Immunoreactive elements were visualized using enhanced chemiluminescence (Immobilon Western Detection Reagents; Millipore). Each experiment was duplicated. 
To analyze membrane cholesterol level, frozen monkey brain tissue was homogenized and then centrifuged at $1000 \times g$ for 10 minutes to obtain a supernatant fraction, as mentioned above. The supernatant (S1) was centrifuged at $13,000 \times g$ for 15 minutes to yield a pellet 2 fraction. The supernatant (S2) from the pellet 2 fraction was centrifuged at $100,000 \times g$ for 1 hour to obtain the microsomal (pellet) fractions. The pellet was resuspended in homogenization buffer and sonicated. This sonicated fraction was layered over homogenization buffer containing 0.85 or $1.2 \mathrm{~mol} / \mathrm{L}$ sucrose and then subjected to discontinuous equilibrium sucrose density gradient centrifugation at $50,000 \times g$ for 30 minutes using a swing-out MLS-50 Beckman rotor (Beckman Coulter, Fullerton, CA). Then, a band was obtained at the 0.32 to $0.85 \mathrm{~mol} / \mathrm{L}$ sucrose interface (myelin), and a band was obtained at the 0.85 to $1.2 \mathrm{~mol} / \mathrm{L}$ sucrose interface fraction (membranes). Free cholesterol level in the membrane fraction was measured by a free cholesterol test E Wako kit (Wako, Osaka, Japan) and normalized by protein concentrations, as measured by bicinchoninic acid assay (Thermo Fisher Scientific, Waltham, MA). Each experiment was duplicated.

\section{Cell Cultures and Chemical Treatments}

A neuronal cell line, mouse neuroblastoma Neuro2a cells from ATCC (Manassas, VA), was grown in Dulbecco's modified Eagle's medium (Sigma) with 5\% fetal calf serum. Cells were cultured under humidified air containing $5 \% \mathrm{CO}_{2}$ at $37^{\circ} \mathrm{C}$. Cells were plated at a density of $2.5 \times 10^{4}$ cells onto 6- or 12-well culture plates (Thermo Fisher Scientific) and coverslips (Matsunami, Osaka, Japan) coated with $0.1 \%$ polyethyleneimine (Wako).

For chemical treatment studies, cells were incubated with $10 \mu \mathrm{mol} / \mathrm{L}$ chloroquine (Wako), $50 \mu \mathrm{mol} / \mathrm{L}$ ciliobrevin D (Millipore), $50 \mathrm{nmol} / \mathrm{L}$ insulin (Wako), or a combination of $10 \mu \mathrm{mol} / \mathrm{L}$ pepstatin A (Sigma), $10 \mu \mathrm{mol} / \mathrm{L}$ E64d (Cayman Chemical), and $10 \mu \mathrm{mol} / \mathrm{L}$ leupeptin (Sigma) for 24 hours. To manipulate membrane cholesterol level, cells were incubated with $75 \mu \mathrm{mol} / \mathrm{L} \mathrm{M} \beta \mathrm{CD}$-cholesterol complex (Sigma) for 1 hour to increase membrane cholesterol levels. For transferrin uptake, cells were pretreated with $75 \mu \mathrm{mol} / \mathrm{L} \mathrm{M} \beta \mathrm{CD}$ cholesterol for 1 hour. After washing, cells were cultured for another 24 hours and then treated with $50 \mathrm{nmol} / \mathrm{L}$ transferrinbiotin (Sigma) for 20 minutes.

Cells that were plated in 12-well plates were lysed in a sample buffer solution containing $62.5 \mathrm{mmol} / \mathrm{L}$ Tris- $\mathrm{HCl}(\mathrm{pH}$ 6.8), $2.3 \%$ SDS, $0.5 \%$ Triton X-100, 2 mmol/L EGTA, $2.5 \%$ 2-mercaptoethanol, and cOmplete Mini protease inhibitor cocktail to extract total cellular proteins. Total proteins were adjusted to $10 \mu \mathrm{g}$ and then subjected to Western blot analyses, as described above. For detection of transferrin-biotin, the membranes were incubated with VECTASTAIN ABC reagent (Vector Laboratories, Burlingame, CA) for 1 hour, and then antigen was detected using enhanced chemiluminescence. Three independent experiments $(n=6$ for each experimental group) were performed, and each experiment was duplicated.
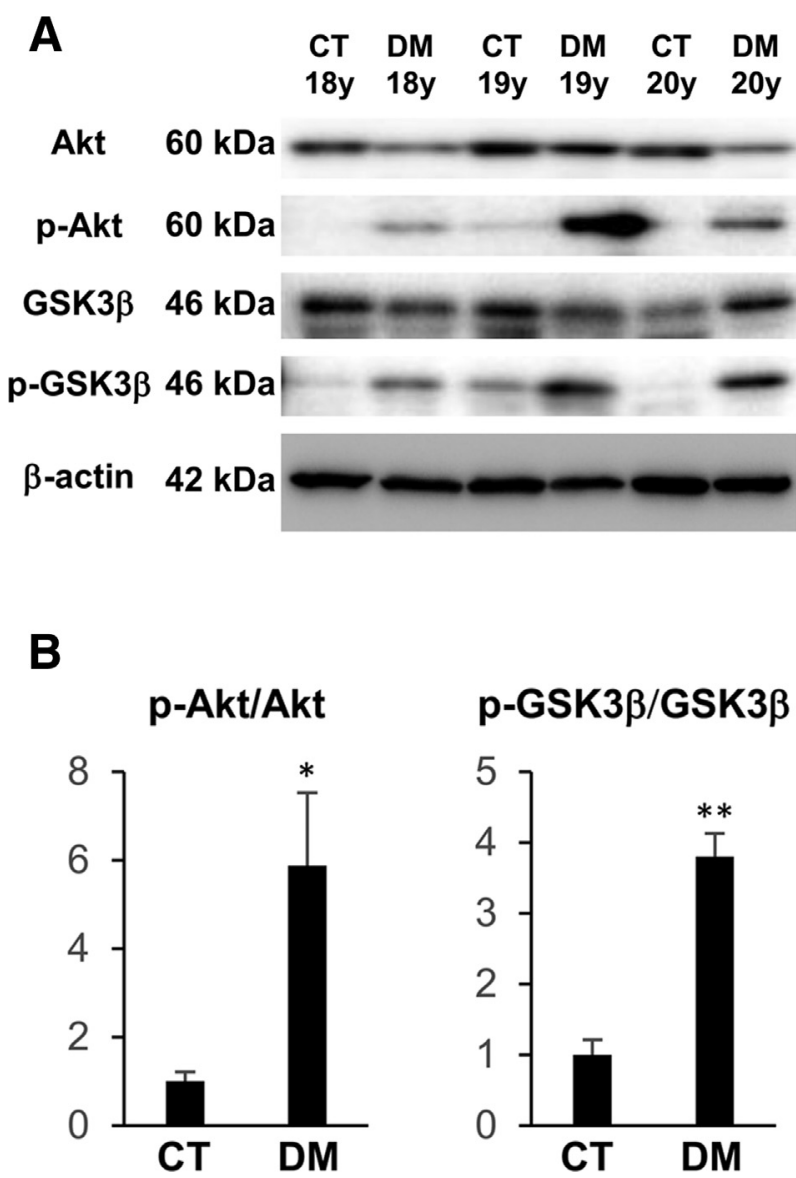

Figure 1 Phosphatidylinositide 3-kinase (PI3K)/Akt pathway is activated in spontaneous T2DM-affected monkey brains. A: Western blot analyses showing the amounts of Akt, p-Akt, GSK3 $\beta, \mathrm{p}$-GSK3 $\beta$, and $\beta$-actin in the brains of normal (CT) and T2DM-affected (DM) monkeys. Monkeys were 18,19 , and 20 years of age (y). B: Relative expression of p-Akt/Akt and $p$ GSK3 $\beta /$ GSK3 $\beta$ in brains from normal and T2DM-affected monkeys. PI3K/Akt pathway was enhanced in spontaneous T2DM-affected monkey brains. p-Akt level was normalized to total Akt level. p-GSK3 $\beta$ level was normalized to total GSK3 $\beta$ level. Data are expressed as means \pm SD (B). $n=3$ (B). ${ }^{*} P<0.05,{ }^{* *} P<0.01$ versus control.

Neuro2a cells that were plated in 6-well plates, as well as tissue from monkey brains, were subjected to measurement of membrane cholesterol levels. Cells were homogenized in homogenate buffer solution and then centrifuged at $1000 \times g$ for 10 minutes to obtain a supernatant fraction. The supernatant $(\mathrm{S} 1)$ was centrifuged at $100,000 \times g$ for 1 hour to obtain the microsomal (pellet) fractions. The pellet was resuspended in homogenization buffer and sonicated. Then, the free cholesterol level in the membrane fraction was measured by a free cholesterol test E Wako kit and normalized by protein concentrations, as measured by bicinchoninic acid assay. Two independent experiments were performed.

\section{Immunofluorescence}

Neuro2a cells that were plated on coverslips were fixed with 4\% paraformaldehyde in phosphate-buffered saline and then 
A

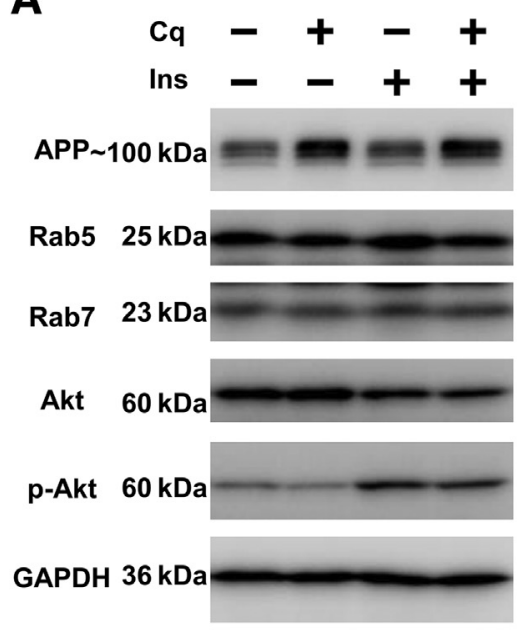

C

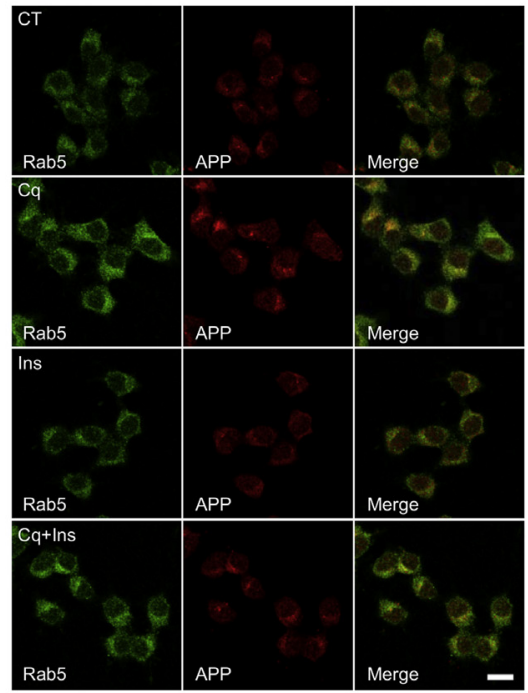

D

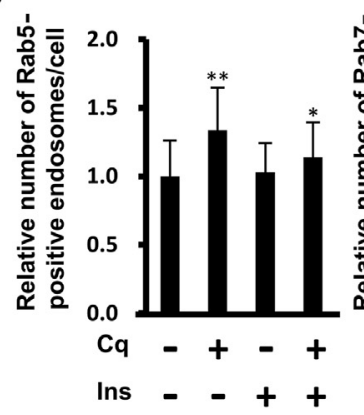

B
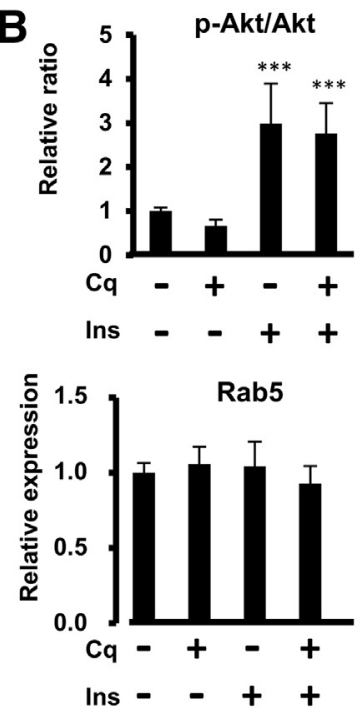

APP
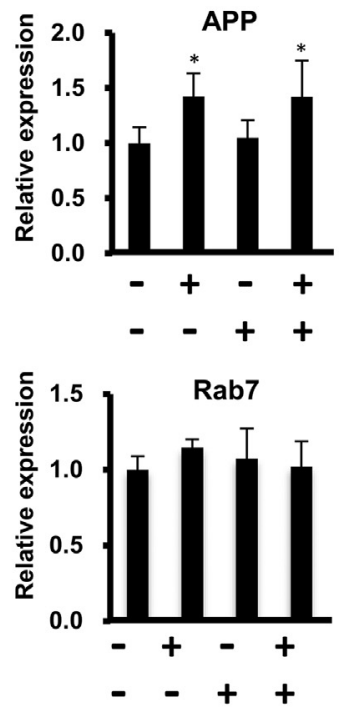

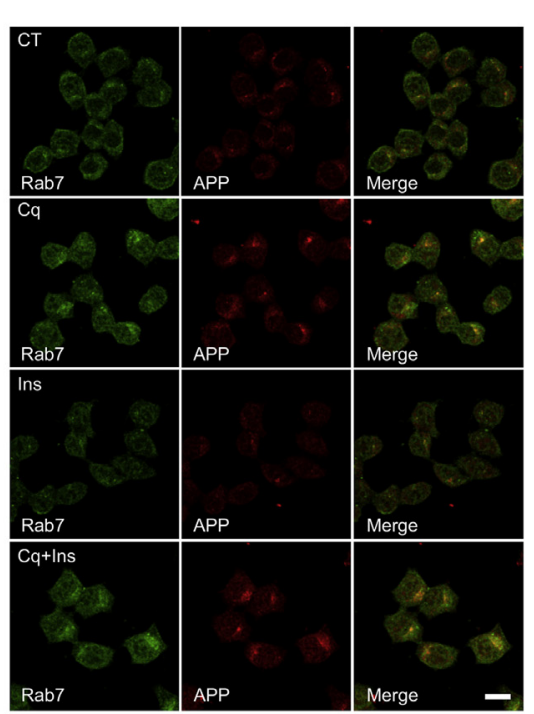

E

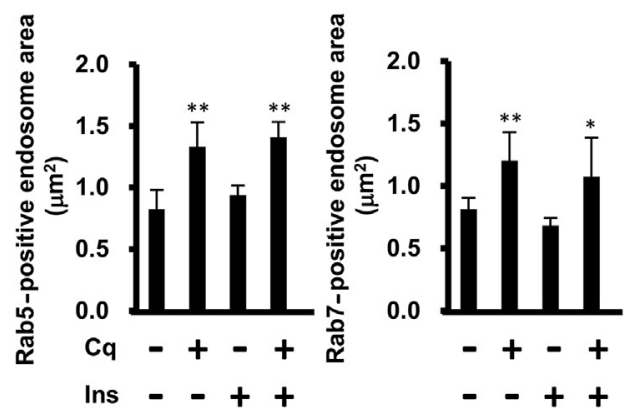

Figure 2 Insulin (Ins) treatment does not alter chloroquine (Cq)-induced endocytic disturbance in Neuro2a cells. Quantitation of molecules in the phosphatidylinositide 3-kinase (PI3K)/Akt pathway, endosome proteins, and $\beta$-amyloid precursor protein (APP) after chloroquine and/or insulin treatment. Neuro2a cells were treated with $10 \mu \mathrm{mol} / \mathrm{L}$ chloroquine and/or $50 \mathrm{nmol} / \mathrm{L}$ insulin for 24 hours. A: Western blot analyses showing the amounts of APP, Rab5, Rab7, p-Akt, Akt, and glyceraldehyde-3-phosphate dehydrogenase (GAPDH) in extracts derived from Neuro2a cells 24 hours after chloroquine and/or insulin treatment. B: Relative amounts of p-Akt/Akt, APP, Rab5, and Rab7 in Neuro2a cells after chloroquine and/or insulin treatment. Insulin treatment activated PI3K/Akt pathway in Neuro2a cells; however, it does not affect APP and Rab GTPases levels. p-Akt level was normalized to total Akt level. APP, Rab5, and Rab7 were normalized to GAPDH. C: Photomicrographs of treated and control (CT) Neuro2a cells immunostained for Rab5, Rab7, and APP 24 hours after chloroquine and/or insulin treatment. Chloroquine treatment induces endocytic pathology in Neuro2a cells. However, insulin treatment does not show any changes. D: Quantitative image analyses of relative number of Rab5- and Rab7positive endosomes for each treatment group. No additional effects are observed by insulin on chloroquine-treated cells. E: Quantitative image analyses of relative area of Rab5- and Rab7-positive endosomes for each treatment group. No additional effects are observed by insulin on chloroquine-treated cells. Data are expressed as means $\pm \mathrm{SD}(\mathbf{B}, \mathbf{D}$, and $\mathbf{E}) . n=6(\mathbf{B}) ; n=20$ (D and E). ${ }^{*} P<0.05,{ }^{* *} P<0.01$, and ${ }^{* *}{ }^{*} P<0.001$ versus control. Scale bars $=40 \mu \mathrm{m}(\mathbf{C}$, all images). 


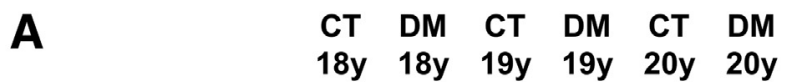

mSREBP2 $55 \mathrm{kDa}$
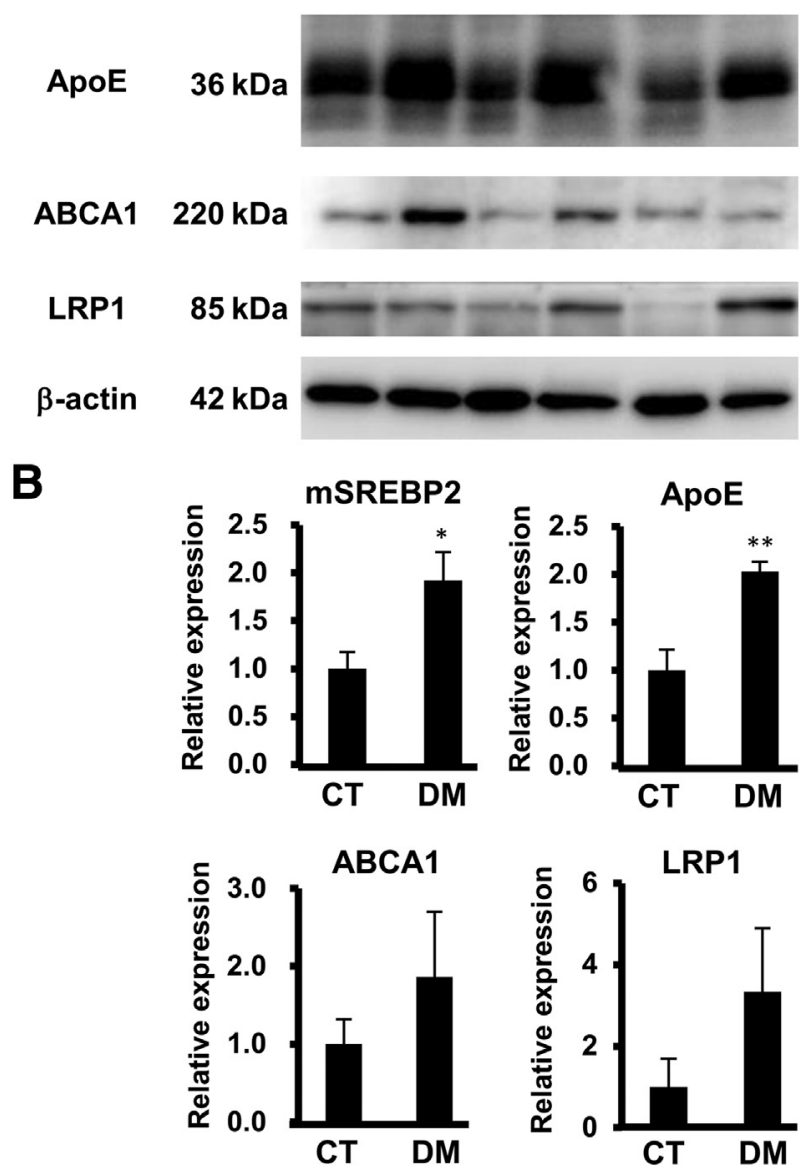

C

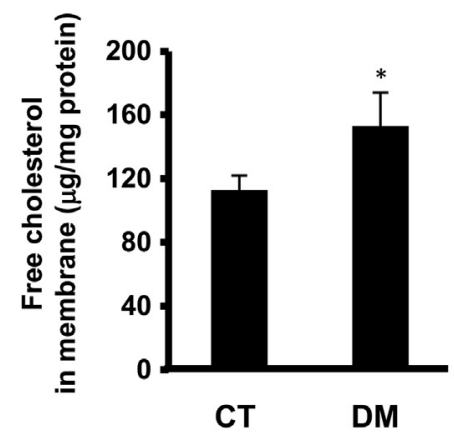

Figure 3 Cholesterol metabolism-related proteins are increased and membrane cholesterol is elevated in T2DM-affected monkey brains. A: Western blot analyses showing the amounts of mature sterol regulatory element-binding protein 2 (mSREBP2), apolipoprotein E (ApoE), ATP-binding cassette subfamily A member 1 (ABCA1), low-density lipoprotein receptor-related protein 1 (LRP1), and $\beta$-actin in normal (CT) and T2DM-affected (DM) monkey brains. B: Relative expression of mSREBP2, ApoE, ABCA1, and LRP1 in brains from normal and T2DMaffected monkeys. mSREBP2, ApoE, ABCA1, and LRP1 levels were normalized to $\beta$ actin levels. Not only mSREBP2 but also cholesterol trafficking-related protein levels in the brains of spontaneous T2DM-affected monkeys are clearly elevated. C: Concentration of free cholesterol levels in membrane fractions derived from the brains of T2DM-affected and control monkeys. Membrane cholesterol levels are significantly elevated in T2DM-affected monkey brains compared with normal control brains. Data are expressed as means \pm SD (B and C). $n=3(\mathbf{B}) ; n=4$ (C). ${ }^{*} P<0.05,{ }^{*} P<0.01$ versus control. $y$, years. permeabilized with $0.1 \%$ Triton $\mathrm{X}-100$ in phosphate-buffered saline for 10 minutes. After blocking with $3 \%$ bovine serum albumin in phosphate-buffered saline and $0.1 \%$ Tween-20, cells were incubated with primary antibodies overnight at $4^{\circ} \mathrm{C}$. After thorough washing, cells were then incubated with AlexaFluor 488-conjugated anti-mouse IgG (1:1000; Jackson ImmunoResearch, Laboratories, Inc., West Grove, PA) and AlexaFluor 568-conjugated anti-rabbit IgG (1:1000; Abcam) for 2 hours at room temperature, and the excess antibody solution was washed out. The stained cells were imaged with an LSM700 confocal laser-scanning microscope (Zeiss, Oberkochen, Germany).

For labeling late endosomes/lysosomes, cells were pretreated with $50 \mathrm{nmol} / \mathrm{L}$ LysoTracker Red DND-99 (Invitrogen, Carlsbad, CA) for 30 minutes before fixation, and then counterstained with DAPI. The particle number and size of endosomes/lysosomes were analyzed by using ImageJ software version $1.49 \mathrm{v}(\mathrm{NIH}$, Bethesda, MD; http://imagej. nih.gov/ij; 20 independent cells were analyzed for each group). Cells were also stained with $100 \mu \mathrm{g} / \mathrm{mL}$ Filipin (70,440; Cayman Chemical) for 1 hour to label cholesterol. Three independent experiments were performed.

\section{A $\beta$ Enzyme-Linked Immunosorbent Assay}

$\mathrm{A} \beta$ level was determined using a sandwich enzyme-linked immunosorbent assay. The enzyme-linked immunosorbent assay kit for Human/Rodent A $\beta 1-40$ was obtained from Wako. Cells plated on 6-well plates were lysed in $70 \%$ formic acid. After incubation at room temperature for 10 minutes, the lysates were further diluted with $1 \mathrm{~mol} / \mathrm{L}$ Tris$\mathrm{HCl}(\mathrm{pH}$ 8.0) and centrifuged at $15,000 \times g$ for 20 minutes. The resulting supernatants were then subjected to enzymelinked immunosorbent assay. Two independent experiments ( $n=6$ for each experimental group) were performed, and all samples were measured in duplicate.

\section{Statistical Analysis}

To bolster reproducibility, immunoreactive bands of the Western blots were quantified using commercially available software (Quantity One version 4.6.6; PDI, Inc., Upper Saddle River, NJ). Data are expressed as means $\pm \mathrm{SD}$. For statistical analyses, data were analyzed by $t$-test to compare between two groups. For comparison of more than three groups, one-way analyses of variance were used, followed by the Tukey honestly significant difference post hoc tests. All statistical analyses were performed with EZR (Saitama Medical Center, Jichi Medical University, Tochigi, Japan), which is a graphical user interface for $\mathrm{R}$ version 2.13.0 (The $\mathrm{R}$ Foundation for Statistical Computing, Vienna, Austria). ${ }^{31}$ More precisely, it is a modified version of $\mathrm{R}$ commander version 1.6-3 that includes statistical functions that are frequently used in biostatistics. Because the number of spontaneous T2DM-affected monkeys was limited, sample calculation or an assessment of the normality of data was not performed. 


\section{Results}

\section{Aberrant Insulin Signal Transduction in T2DM-Affected Monkey Brains}

T2DM is characterized by peripheral insulin resistance and aberrant insulin signal transduction. ${ }^{32}$ When binding to insulin receptors, insulin induces signal transduction of various downstream molecules, such as those in the phosphatidylinositide 3-kinase (PI3K)/Akt pathway. ${ }^{33}$ Several studies showed that alteration in PI3K activity can affect endosome trafficking. ${ }^{34-36}$ Although there are limitations such that the number of available animals is relatively small, signal transduction was analyzed in the PI3K/Akt pathway to assess whether PI3K activity is altered in spontaneous T2DMaffected monkey brains. Akt and GSK3 $\beta$, the major molecules of the PI3K/Akt pathway, are highly phosphorylated in spontaneous T2DM-affected monkey brains compared with age-matched normal monkey brains (Figure 1).

\section{Insulin Treatment Neither Induces nor Enhances Endocytic Disturbance}

To assess whether up-regulation in the PI3K/Akt pathway enhances endocytic disturbance, insulin was applied to cultured Neuro2a cells, a mouse neuroblastoma cell line, and the expression of molecules in the PI3K/Akt pathway, endosome proteins, and APP was quantified. Insulin treatment in vitro clearly induces phosphorylation of Akt in Neuro2a cells (Figure 2, A and B). Rab GTPase is a good indicator of alterations in intracellular endosome trafficking. ${ }^{13,37,38}$ Herein, insulin treatment alone did not affect APP levels or subcellular distribution of Rab5- and Rab7-positive endosomes (Figure 2, $\mathrm{A}-\mathrm{C}$ ). Chloroquine, a lysosomotropic reagent, disturbs endosome/lysosome trafficking and lysosomal degradation by alkalinizing endosomal $\mathrm{pH}$, leading to significant endocytic disturbance. ${ }^{13,39-41}$ Consistent with previous studies, ${ }^{40,41}$ chloroquine treatment increased APP levels in Neuro2a cells (Figure 2, A and B). Immunocytochemistry also confirmed that chloroquine treatment reproduced endocytic pathology, such as APP accumulation, in enlarged Rab5- and Rab7-positive endosomes (Figure 2C). Quantitative image analyses confirmed that chloroquine treatment increased the number of both Rab5- and Rab7-positive endosomes, and their size was also enlarged (Figure 2, D and E). On the other hand, no additional effects of chloroquine-induced endocytic disturbance were observed with insulin treatment (Figure 2).

\section{Cholesterol Metabolism-Related Proteins Are Increased, and Membrane Cholesterol Level Is Elevated, in T2DM-Affected Monkey Brains}

Dyslipidemia is also frequently observed in T2DM patients. ${ }^{42-45}$ Alterations in cholesterol homeostasis have been suggested to be associated with $\mathrm{AD}$ pathology. ${ }^{46}$ This observation prompted us to analyze cholesterol metabolism-related proteins in spontaneous T2DM-affected monkey brains.

When cellular membrane cholesterol level is decreased, SREBP2 is translocated from endoplasmic reticulum to Golgi by SREBP cleavage-activating protein and cleaved into a mature form, which induces cholesterol synthesis. ${ }^{47,48}$ Mature SREBP2 was clearly increased in spontaneous T2DM-affected monkey brains (Figure 3, A and B). Moreover, cholesterol trafficking-related protein levels, such as ApoE, ATP-binding cassette subfamily A member 1 , and low-density lipoprotein receptor-related protein 1, were also increased in spontaneous T2DMaffected monkey brains (Figure 3, A and B).

Much of the cholesterol in the brain is found in myelin, where cholesterol turnover is slow. ${ }^{49}$ To assess whether cholesterol level is abnormally altered in T2DM-affected brains, the brain-derived membrane fraction was purified by removing myelin using sucrose gradient centrifugation. Noteworthy, the amount of membrane cholesterol was significantly elevated in spontaneous T2DM-affected monkey brains compared with normal control brains (Figure 3C).

Previous study showed that insulin regulates cholesterol level via modifying SREBP2 level. ${ }^{50}$ Although insulin treatment slightly increased mature SREBP2 level in Neuro2a cells, other cholesterol trafficking-related protein levels were not affected (Supplemental Figure S2, A and B). Insulin treatment also failed to increase the level of membrane cholesterol in Neuro2a cells (Supplemental Figure S2C).

\section{Increase in Membrane Cholesterol Levels Enhances Endocytic Disturbance to Augment Intracellular Accumulation of APP and $A \beta$}

To assess whether elevated membrane cholesterol enhances endocytic disturbance, Neuro2a cells were treated with M $\beta C D$-cholesterol, a chemical commonly used to load membrane cholesterol. The cellular membrane cholesterol was increased after M $\beta C D$-cholesterol treatment (Figure 4, $\mathrm{A}$ and $\mathrm{B}$ ). Although chloroquine treatment alone did not affect membrane cholesterol level, it significantly enhanced membrane cholesterol when combined with MBCDcholesterol treatment (Figure 4, A and B). M $\beta C D$-cholesterol treatment alone did not affect APP or Rab GTPase levels (Figure 4, C and D). However, M $\beta C D$-cholesterol in combination with chloroquine significantly enhanced the increase in APP and Rab7 levels even more (Figure 4, C and D). Rab5 level also tended to increase when MBCDcholesterol and chloroquine treatment were combined (Figure 4, C and D).

Immunocytochemistry of cells in this experiment showed that enlarged Rab5- and Rab7-positive endosomes appeared to increase, and large amounts of APP accumulated in the enlarged endosomes when combining M $\beta C D$-cholesterol and chloroquine treatment (Figure 4E). Quantitative image analyses confirmed that $\mathrm{M} \beta \mathrm{CD}$-cholesterol treatment 

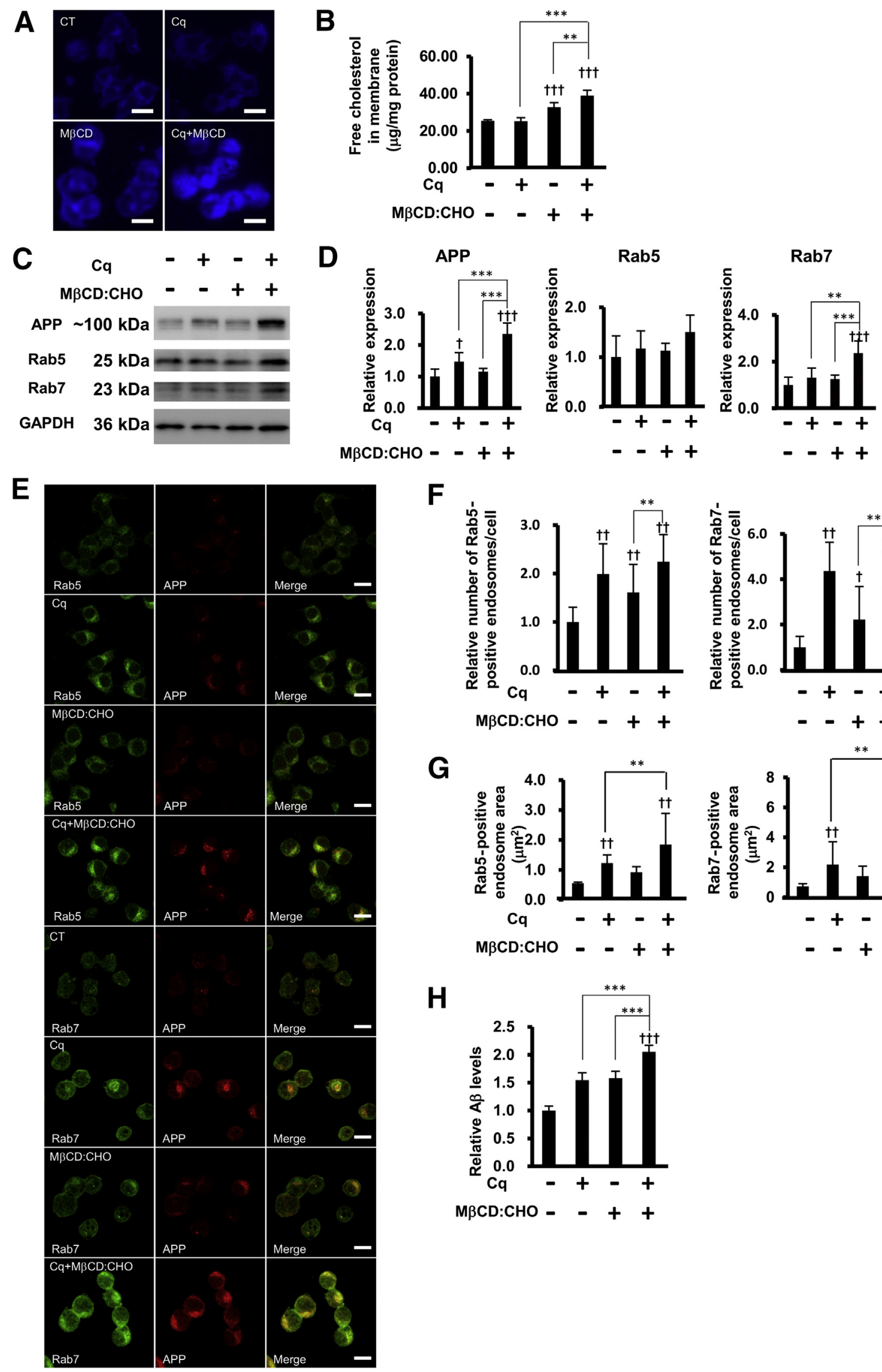

F
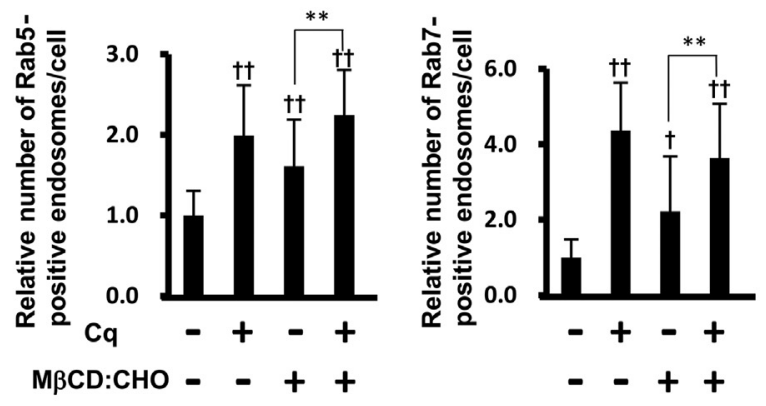

G
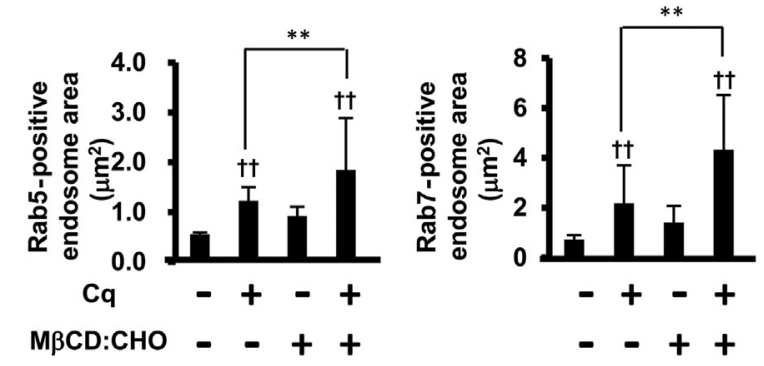

H

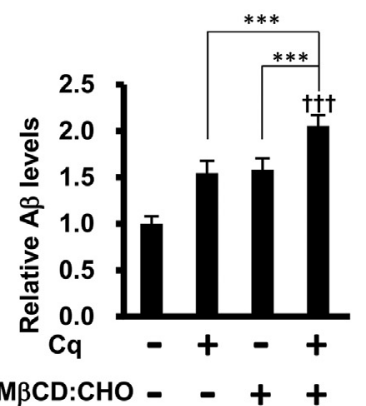


increased the number of Rab5- and Rab7-positive endosomes by itself, and M $B C D$-cholesterol in combination with chloroquine strongly enhanced the size of both endosomes (Figure 4, $\mathrm{F}$ and $\mathrm{G}$ ). Intracellular $\mathrm{A} \beta$ level was also significantly increased in cells treated with both M $\beta C D$ cholesterol and chloroquine compared with chloroquine treatment alone (Figure $4 \mathrm{H}$ ). Intriguingly, M $\beta C D$-cholesterol treatment solely induced intracellular accumulation of $\mathrm{A} \beta$ (Figure $4 \mathrm{H}$ ).

Aging disrupts the ability of dynein-mediated transport in brain, and dynein dysfunction reproduces endocytic pathology, resulting in the intracellular accumulation of $\mathrm{A} \beta{ }^{12,13}$ Ciliobrevin D is a well-known cytoplasmic dynein inhibitor, and it can induce modest endocytic disturbance compared with chloroquine (Supplemental Figure S3). Evidently, M $\beta C D$-cholesterol treatment also enhanced ciliobrevin $\mathrm{D}$-induced endocytic disturbance to augment intracellular accumulation of A $\beta$ (Supplemental Figure S3).

\section{Elevated Membrane Cholesterol Disturbs Lysosomal Degradation}

Because M $\beta C D$-cholesterol treatment alone induced the intracellular accumulation of $\mathrm{A} \beta$ (Figure $4 \mathrm{H}$ ), it was considered that elevated membrane cholesterol might alter APP metabolism. Several studies showed that A $\beta$ generation is affected by alterations in endocytosis of APP and that endocytosis-related proteins, such as clathrin and dynamin, are involved in APP metabolism. ${ }^{51-54}$ MBCDcholesterol treatment did not affect the levels of clathrin and dynamin in Neuro2a cells (Supplemental Figure S4, A and B). Immunocytochemistry showed that the subcellular distribution of clathrin and dynamin remained unchanged with the increase in membrane cholesterol levels (Supplemental Figure S4C). Also, transferrin uptake was not affected by M $\beta C D$-cholesterol treatment (Supplemental Figure S4, D and E).

Previous studies showed that the manipulation of membrane cholesterol level alters APP metabolism to increase $\beta$-site cleavage, resulting in the increase of $A \beta$ generation. ${ }^{55-59}$ In the present study, however, no changes were observed in $\alpha$ - and $\beta$-site cleaved products of
APP with M $\beta C D$-cholesterol treatment (Supplemental Figure S5).

The endolysosomal system is also important for APP metabolism, and lysosomal dysfunction is closely associated with the development of $A \beta$ pathology in the brains of $A D$ patients. ${ }^{60}$ Especially, autophagy mediates not only $A \beta$ generation but also $A \beta$ clearance, and the clearance of autophagic vacuoles is significantly impaired in AD patient brains. ${ }^{61}$ Therefore, we hypothesized that elevated membrane cholesterol might disturb the lysosomal degradation. The morphology of late endosomes/lysosomes was analyzed by using LysoTracker. Combined treatment with M $\beta C D$ cholesterol and chloroquine greatly increased the number of abnormally enlarged late endosomes/lysosomes compared with chloroquine treatment alone (Figure 5, A and B). The size of LysoTracker-positive late endosomes/lysosomes was also enhanced by combined treatment with $\mathrm{M} \beta \mathrm{CD}$ cholesterol and chloroquine (Figure 5, A and C).

Lysosomal degradation was also assessed biochemically. p62/SQSTM1, a ubiquitin binding protein, and microtubuleassociated protein 1 LC3 are involved in autophagic clearance, and the levels of p62 and LC3-II are good indicators of lysosomal degradation. ${ }^{61,62}$ Noteworthy, MBCD-cholesterol treatment increased both p62 and LC3-II levels, and it dramatically enhanced chloroquine-induced p62 and LC3-II levels (Figure 5, D and E, and Supplemental Figure S6). M $\beta C D$-cholesterol treatment also enhanced ciliobrevin D-induced p62 and LC3-II levels (Supplemental Figure S3). On the other hand, insulin treatment did not affect the levels of p62 and LC3-II, and it did not enhance chloroquine-induced p62 and LC3-II levels either (Supplemental Figure S7).

\section{Inhibition of Lysosomal Degradation also Enhances Chloroquine-Induced Endocytic Disturbance to Augment Intracellular Accumulation of $A \beta$}

To assess whether additional lysosomal dysfunction enhances chloroquine-induced endocytic disturbance, cultured Neuro2a cells were treated with a mixture of inhibitors of various subtypes of cathepsins, which are typical lysosomal hydrolases. This mixture consisted of pepstatin A, E64d,

\footnotetext{
Figure 4 Elevated membrane cholesterol aggravates chloroquine $(\mathrm{Cq})$-induced endocytic disturbance, leading to enhanced intracellular accumulation of APP and A 3 . Neuro2a cells were treated in vitro with $75 \mu \mathrm{mol} / \mathrm{L}$ MBCD-cholesterol (CHO) for 1 hour to experimentally load membrane cholesterol. After washing, cells were cultured for another 24 hours with $10 \mu \mathrm{mol} / \mathrm{L}$ chloroquine to disrupt endosome/lysosome trafficking. A: Photomicrographs of Neuro2a cells stained with $100 \mu \mathrm{g} / \mathrm{mL}$ Filipin 24 hours after chloroquine and/or M $\beta C D$-cholesterol treatment. M $\beta C D$-cholesterol treatment increases Filipin-positive fluorescence, and combined treatment of $M \beta C D$-cholesterol and chloroquine strongly enhances it. B: Concentration of free cholesterol in membrane fraction derived from Neuro2a cells after chloroquine and/or M $\beta C D$-cholesterol treatment. C: Western blot analyses showing the amounts of $\beta$-amyloid precursor protein (APP), Rab5, Rab7, and glyceraldehyde-3-phosphate dehydrogenase (GAPDH) in extracts derived from Neuro2a cells after chloroquine and/or M $\beta C D-c h o l e s t e r o l$ treatment. D: Relative expression of APP, Rab5, and Rab7 in Neuro2a cells, showing the effect of M $\beta C D$-cholesterol and chloroquine treatment. APP, Rab5, and Rab7 levels were normalized to GAPDH levels. E: Photomicrographs of MBCD-cholesterol- and chloroquine-treated Neuro2a cells immunostained for Rab5 and APP or Rab7 and APP. F: Quantitative image analyses of relative number of Rab5- and Rab7-positive endosomes for each treatment group. G: Quantitative image analyses of relative area of Rab5- and Rab7-positive endosomes for each treatment group. H: Relative amounts of A $\beta$ in Neuro2a cells after M $\beta C D-$ cholesterol and chloroquine treatment. $A \beta$ levels were measured by enzyme-linked immunosorbent assay. Data are expressed as means \pm SD (B, D, and $\mathbf{F}-\mathbf{H})$. $n=6(\mathbf{B}, \mathbf{D}$, and $\mathbf{H}) ; n=20(\mathbf{F}$ and $\mathbf{G}) .{ }^{*} P<0.05,{ }^{*} P<0.01$, and ${ }^{* * *} P<0.001{ }^{\dagger}{ }^{\dagger} P<0.05,{ }^{\dagger \dagger} P<0.01$, and ${ }^{\dagger \dagger \dagger} P<0.001$ versus control. Scale bar $=40 \mu \mathrm{m}$ (A and $\mathbf{E}$, all images). CT, control cell.
} 

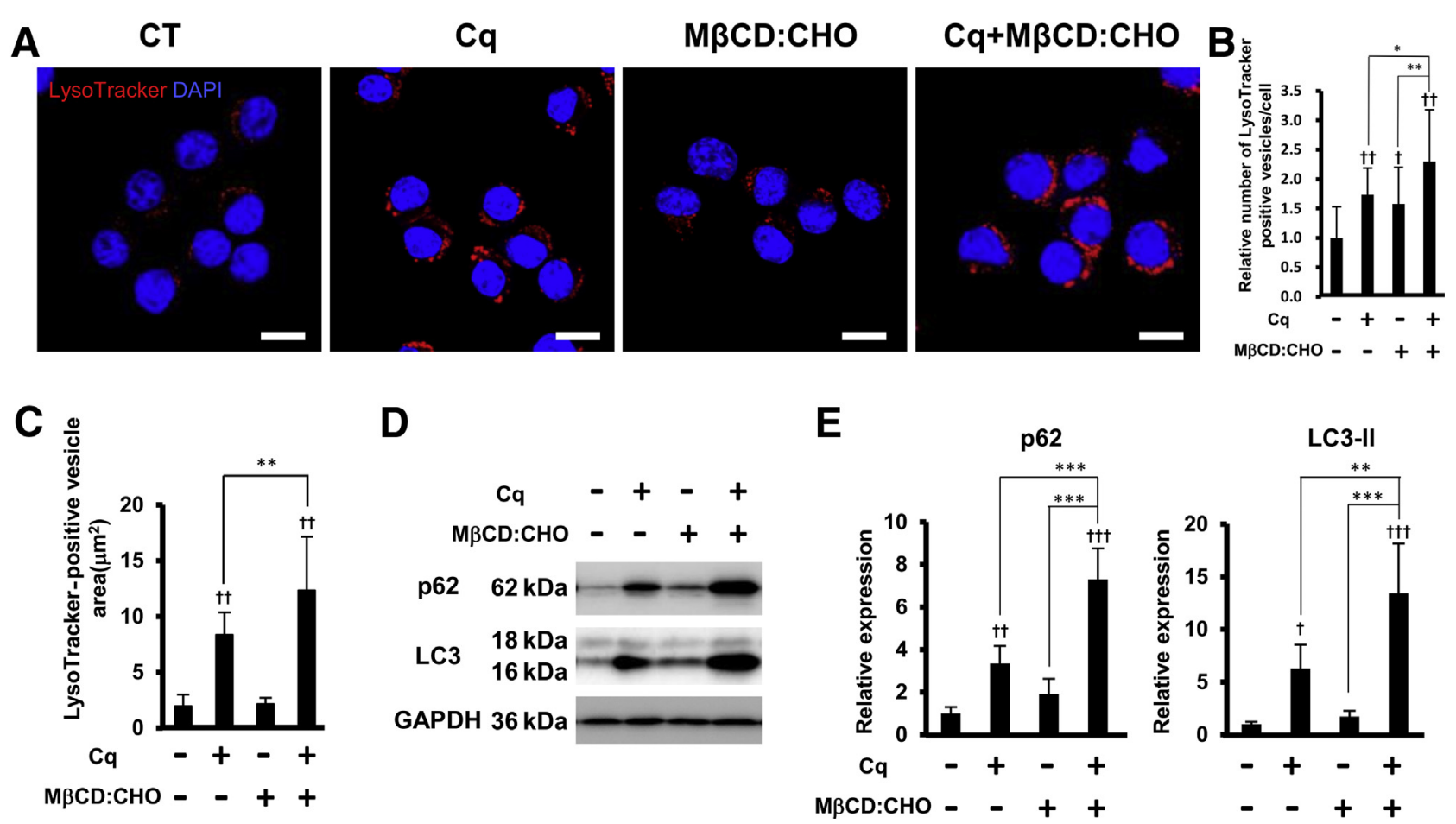

Figure 5 Lysosomal dysfunction is exacerbated by $M \beta C D$-cholesterol (CHO) treatment. Neuro2a cells were treated with $75 \mu \mathrm{mol} / \mathrm{L} M \beta C D$-cholesterol for 1 hour. After washing, cells were cultured for another 24 hours with $10 \mu \mathrm{mol} / \mathrm{L}$ chloroquine $(\mathrm{Cq})$ to disrupt endosome/lysosome trafficking. A: Photomicrographs of Neuro2a cells stained with $50 \mathrm{nmol} / \mathrm{L}$ LysoTracker Red DND-99 for 30 minutes before fixation and counterstained for labeling cell nuclei with DAPI. Combined treatment of $M B C D$-cholesterol and chloroquine enhances the enlargement of LysoTracker-positive lysosomes/late endosomes. B: Quantitative image analyses of relative number of LysoTracker-positive lysosomes/late endosomes for each treatment group. C: Quantitative image analyses of relative area of LysoTracker-positive lysosomes/late endosomes for each treatment group. D: Western blot analyses showing the amounts of p62, light chain 3 (LC3)-II, and glyceraldehyde-3-phosphate dehydrogenase (GAPDH) in extracts derived from Neuro2a cells after M $\beta C D$-cholesterol and/or chloroquine treatment. E: Relative expression of p62 and LC3-II, substrates of lysosomal degradation, in Neuro2a cells, showing the effect of MBCD-cholesterol and chloroquine treatment. p62 and LC3-II levels were normalized to GAPDH levels. Data are expressed as means \pm SD (B, C, and E). $n=20(\mathbf{B}$ and $\mathbf{C}) ; n=6(\mathbf{E})$. ${ }^{*} P<0.05, * * P<0.01$, and $* * * P<0.001 ;{ }^{\dagger} P<0.05,{ }^{\dagger \dagger} P<0.01$, and ${ }^{\dagger \dagger} P<0.001$ versus control. Scale bars $=40 \mu \mathrm{m}(\mathbf{A})$. CT, control cell.

and leupeptin (PEL). Although PEL treatment did not alter APP levels when applied alone in the absence of chloroquine-induced endocytic disturbance, it significantly enhanced the increase of APP after chloroquine treatment.
The same was true for p62 and LC3-II in chloroquinetreated Neuro2a cells (Figure 6, A and B). It is noteworthy that PEL treatment also augmented $A \beta$ accumulation in chloroquine-treated cells (Figure 6C).
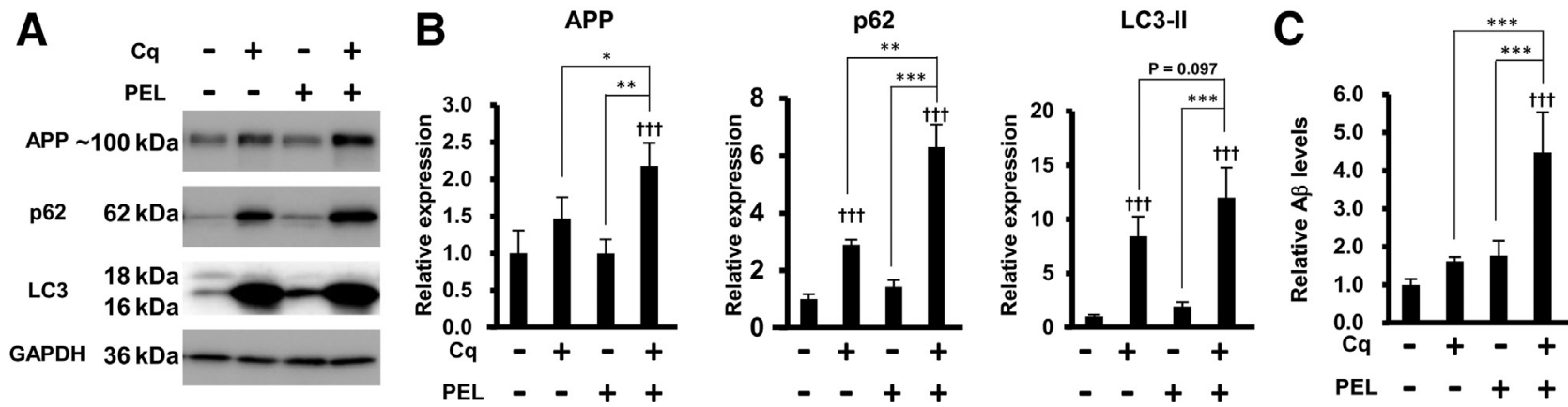

Figure 6 Inhibition of lysosomal degradation enhances intracellular accumulation of $\beta$-amyloid precursor protein (APP) and A $\beta$ induced by chloroquine (Cq). Neuro2a cells were treated with $10 \mu \mathrm{mol} / \mathrm{L}$ chloroquine to induce endocytic dysfunction and/or a mixture of $10 \mu \mathrm{mol} / \mathrm{L}$ pepstatin $\mathrm{A}, 10 \mu \mathrm{mol} / \mathrm{L} \mathrm{E64d,} \mathrm{and}$ $10 \mu \mathrm{mol} / \mathrm{L}$ leupeptin (PEL) for 24 hours to induce lysosomal dysfunction. A: Western blot analyses showing the amounts of APP, p62, light chain 3 (LC3)-II, and glyceraldehyde-3-phosphate dehydrogenase (GAPDH) in extracts derived from Neuro2a cells after chemical treatment. B: Relative expression of APP, p62, and LC3-II in Neuro2a cells, showing the effect of chloroquine and/or PEL. APP, p62, and LC3-II levels were normalized to GAPDH levels. PEL treatment aggravates chloroquine-induced endocytic disturbance. C: Relative amounts of $A \beta$ in Neuro2a cells, showing the effect of chloroquine and/or PEL. A $\beta$ levels were measured by enzyme-linked immunosorbent assay. Combined treatment of chloroquine and PEL strongly enhances intracellular accumulation of $A \beta$ in Neuro2a cells. Data are expressed as means \pm SD (B and C). $n=6$ (B and C). ${ }^{*} P<0.05,{ }^{* *} P<0.01$, and ${ }^{* * *} P<0.001 ;{ }^{\dagger} P<0.05,{ }^{\dagger \dagger} P<0.01$, and ${ }^{\dagger \dagger \dagger} P<$ 0.001 versus control. 


\section{Discussion}

It is widely known that insulin signaling is impaired in T2DM patients and that aberrant insulin signaling is also involved in AD pathology ${ }^{63-65} \mathrm{PI} 3 \mathrm{~K}$ is an important kinase that mediates insulin signaling, especially within the PI3K/Akt pathway. ${ }^{33-36}$ In spontaneous T2DM-affected monkey brains, Akt phosphorylation level was clearly up-regulated, suggesting that PI3K activity is enhanced (Figure 1). However, the insulin treatment study failed to reproduce endocytic disturbance, and it did not show any additional effects on chloroquine-induced endocytic disturbance in Neuro2a cells (Figure 2). Although we acknowledge the limitations of the in vitro experimental model in this study, the up-regulation of PI3K may not be responsible for the enhancement of endocytic disturbance in T2DM-affected brains.

Disrupted lipid metabolism is also an important feature of T2DM, and alterations in cholesterol homeostasis have been suggested to be associated with AD pathology. ${ }^{42-46}$ In the present study, cholesterol metabolism-related protein levels, such as mature SREBP2, ApoE, ATP-binding cassette subfamily A member 1, and low-density lipoprotein receptor-related protein 1 , were totally increased in spontaneous T2DM-affected monkey brains (Figure 3, A and B). Noteworthy, membrane cholesterol level is clearly elevated in spontaneous T2DM-affected monkey brain (Figure 3C). To our knowledge, this is the first evidence that spontaneous T2DM increases the amount of membrane cholesterol in the brain of nonhuman primates. This finding prompted us to analyze the impact of elevated membrane cholesterol level on endocytosis. In our study, experimental load of membrane cholesterol in cultured Neuro2a cells enhances chloroquineand ciliobrevin D-induced endocytic disturbance, resulting in great accumulation of APP and A $\beta$ (Figure 4 and Supplemental Figure S3). Interestingly, chloroquine treatment did not affect membrane cholesterol level; however, it increased membrane cholesterol level remarkably after M $\beta C D$-cholesterol treatment (Figure 4, A and B). This finding suggests that endocytic disturbance can be a risk factor for abnormal membrane cholesterol metabolism. On the other hand, insulin treatment did not affect cholesterol trafficking-related protein levels, and it failed to increase membrane cholesterol level in Neuro2a cells (Supplemental Figure S2). These findings suggest that the alteration of cholesterol metabolism in T2DM-affected brain would be independent of aberrant insulin signaling.

M $\beta C D$-cholesterol applied by itself resulted in elevated intracellular $A \beta$ levels, suggesting that the increase in membrane cholesterol levels alters APP metabolism (Figure $4 \mathrm{H}$ ). In the present study, M $\beta C D$-cholesterol treatment did not affect the levels or subcellular distribution of clathrin and dynamin, and no changes were observed in transferrin uptake with experimental load of membrane cholesterol (Supplemental Figure S4). Moreover, APP cleavage also remained unchanged with $\mathrm{M} \beta \mathrm{CD}$-cholesterol treatment (Supplemental Figure S5). These findings suggest that elevated membrane cholesterol may not affect $A \beta$ generation in the present study.

Strikingly, M $\beta C D$-cholesterol treatment increased the levels of substrates for lysosomal degradation, p62 and LC3-II, and it significantly enhanced chloroquine-induced intracellular accumulation of p62 and LC3-II (Figure 5, D and E, and Supplemental Figure S6). The results of this study are consistent with the previous finding that LC3-II level was significantly increased in T2DM-affected monkey brains. ${ }^{28}$ Lysosomal dysfunction can induce endocytic disturbance by itself, and several other studies support this, showing that the accumulation of cholesterol in late endosome and/or lysosome disrupts lysosomal degradation. ${ }^{66-69}$ Moreover, a recent study showed that cholesterol enrichment impairs autophagy-mediated $\mathrm{A} \beta$ clearance even in vivo. ${ }^{70}$ These results suggest that the effect of M $\beta C D$ cholesterol treatment persists even in the lysosome, and an increase of plasma membrane cholesterol level may be enough to disrupt lysosomal degradation (Figure 5, D and E). Moreover, the PEL treatment study confirmed that lysosomal dysfunction can enhance chloroquine-induced endocytic disturbance (Figure 6).

It remains unclear which is responsible for age-related $A \beta$ pathology, endosome trafficking disturbance or lysosomal dysfunction. Chloroquine primarily alters endosome trafficking via alkalizing endosomal $\mathrm{pH}$, leading to lysosomal dysfunction. ${ }^{39}$ In the present study, APP level was increased by chloroquine treatment but not by PEL treatment, suggesting that APP accumulation may be caused by endosome trafficking disturbance rather than lysosomal dysfunction (Figure 6, A and B). This idea is reasonable because the immunocytochemical results showed that the accumulated APP is abundant in Rab5- and Rab7-positive endosomes of chloroquine-treated cells (Figure 2C). On the other hand, $\mathrm{A} \beta$ level increased as a result of each treatment alone, and the combination of chloroquine and PEL treatment enhanced $A \beta$ accumulation even more (Figure 6C). These findings suggest that both endosome trafficking disturbance and lysosomal dysfunction can induce $A \beta$ pathology, and their additive combination could possibly lead to an even worse scenario in the unfolding of $\mathrm{AD}$ pathogenesis.

In conclusion, we provided evidence that spontaneous T2DM leads to the increase of membrane cholesterol level in nonhuman primate brain, and such elevated membrane cholesterol can enhance endocytic disturbance via lysosomal dysfunction. Postmortem brain analysis of $\mathrm{AD}$ patients shows that cholesterol levels were elevated compared with age-matched normal controls. ${ }^{71,72}$ ApoE is the most abundant lipoprotein in brain and is crucial for transporting cholesterol among various types of cells. ${ }^{73,74}$ Of the three ApoE alleles-ApoE- $\varepsilon 2, \quad A p o E-\varepsilon 3$, and ApoE- $\varepsilon 4$ (ApoE4) - having ApoE4 is the strongest genetic risk factor for developing late-onset $\mathrm{AD} .^{75-77} \mathrm{~A}$ recent study showed that cortical cholesterol level is higher in human ApoE4targeted replacement mice than ApoE- $\varepsilon 2$ or ApoE- $\varepsilon 3$. $^{78}$ Hence, ApoE4 may also play out its role in $\mathrm{AD}$ 
pathogenesis via an increase of membrane cholesterol level. In other words, abnormally high membrane cholesterol levels could be a risk factor for developing $\mathrm{AD}$, which could come about through having T2DM and/or harboring the ApoE4 allele. Several clinical studies have reported that statins, well-known cholesterol-lowering drugs, have some potential effects related to preventing or delaying the development of AD. ${ }^{79}$ Although further investigations are needed to clarify how T2DM alters cerebral lipid metabolism to induce elevated membrane cholesterol levels in the brain, restoring normal cholesterol metabolism may be a potential therapeutic target for preventing the development of AD.

\section{Supplemental Data}

Supplemental material for this article can be found at https://doi.org/10.1016/j.ajpath.2018.10.011.

\section{References}

1. Selkoe DJ: The molecular pathology of Alzheimer's disease. Neuron 1991, 6:487-498

2. Armstrong RA: The molecular biology of senile plaques and neurofibrillary tangles in Alzheimer's disease. Folia Neuropathol 2009, 47: 289-299

3. Hardy J, Selkoe DJ: The amyloid hypothesis of Alzheimer's disease: progress and problems on the road to therapeutics. Science 2002, 297: 353-356

4. Lee HG, Casadesus G, Zhu X, Joseph JA, Perry G, Smith MA: Perspectives on the amyloid-beta cascade hypothesis. J Alzheimers Dis 2004, 6:137-145

5. Haass C, Koo EH, Mellon A, Hung AY, Selkoe DJ: Targeting of cellsurface beta-amyloid precursor protein to lysosomes: alternative processing into amyloid-bearing fragments. Nature 1992, 357: $500-503$

6. Koo EH, Squazzo SL: Evidence that production and release of amyloid beta-protein involves the endocytic pathway. J Biol Chem 1994, 269:17386-17389

7. Soriano S, Chyung AS, Chen X, Stokin GB, Lee VM, Koo EH: Expression of beta-amyloid precursor protein-CD3gamma chimeras to demonstrate the selective generation of amyloid beta(1-40) and amyloid beta(1-42) peptides within secretory and endocytic compartments. J Biol Chem 1999, 274:32295-32300

8. Cataldo AM, Paskevich PA, Kominami E, Nixon RA: Lysosomal hydrolases of different classes are abnormally distributed in brains of patients with Alzheimer disease. Proc Natl Acad Sci U S A 1991, 88: 10998-11002

9. Cataldo AM, Barnett JL, Pieroni C, Nixon RA: Increased neuronal endocytosis and protease delivery to early endosomes in sporadic Alzheimer's disease: neuropathologic evidence for a mechanism of increased beta-amyloidogenesis. J Neurosci 1997, 17:6142-6151

10. Cataldo AM, Peterhoff CM, Troncoso JC, Gomez-Isla T, Hyman BT, Nixon RA: Endocytic pathway abnormalities precede amyloid beta deposition in sporadic Alzheimer's disease and Down syndrome: differential effects of APOE genotype and presenilin mutations. Am J Pathol 2000, 157:277-286

11. Cataldo AM, Petanceska S, Terio NB, Peterhoff CM, Durham R, Mercken M, Mehta PD, Buxbaum J, Haroutunian V, Nixon RA: Abeta localization in abnormal endosomes: association with earliest Abeta elevations in AD and Down syndrome. Neurobiol Aging 2004, $25: 1263-1272$
12. Kimura N, Imamura O, Ono F, Terao K: Aging attenuates dynactindynein interaction: down-regulation of dynein causes accumulation of endogenous tau and amyloid precursor protein in human neuroblastoma cells. J Neurosci Res 2007, 85:2909-2916

13. Kimura $N$, Inoue $M$, Okabayashi S, Ono F, Negishi T: Dynein dysfunction induces endocytic pathology accompanied by an increase in Rab GTPases: a potential mechanism underlying age-dependent endocytic dysfunction. J Biol Chem 2009, 284:31291-31302

14. Harold D, Abraham R, Hollingworth P, Sims R, Gerrish A, Hamshere ML, et al: Genome-wide association study identifies variants at CLU and PICALM associated with Alzheimer's disease. Nat Genet 2009, 41:1088-1093

15. Seshadri S, Fitzpatrick AL, Ikram MA, DeStefano AL, Gudnason V, Boada M, et al: Genome-wide analysis of genetic loci associated with Alzheimer disease. JAMA 2010, 303:1832-1840

16. Vardarajan BN, Bruesegem SY, Harbour ME, Inzelberg $\mathrm{R}$, Friedland R, St George-Hyslop P, Seaman MN, Farrer LA: Identification of Alzheimer disease-associated variants in genes that regulate retromer function. Neurobiol Aging 2012, 33:2231. e15-2231.e30

17. Chouraki V, Seshadri S: Genetics of Alzheimer's disease. Adv Genet 2014, 87:245-294

18. Talwar P, Silla Y, Grover S, Gupta M, Agarwal R, Kushwaha S, Kukreti R: Genomic convergence and network analysis approach to identify candidate genes in Alzheimer's disease. BMC Genomics 2014, 15:199

19. Saavedra L, Mohamed A, Ma V, Kar S, de Chaves EP: Internalization of beta-amyloid peptide by primary neurons in the absence of apolipoprotein E. J Biol Chem 2007, 282:35722-35732

20. Ovsepian SV, Antyborzec I, O'Leary VB, Zaborszky L, Herms J, Oliver Dolly J: Neurotrophin receptor p75 mediates the uptake of the amyloid beta $(\mathrm{A} \beta)$ peptide, guiding it to lysosomes for degradation in basal forebrain cholinergic neurons. Brain Struct Funct 2014, 219:1527-1541

21. Leibson CL, Rocca WA, Hanson VA, Cha R, Kokmen E, O'Brien PC, Palumbo PJ: Risk of dementia among persons with diabetes mellitus: a population-based cohort study. Am J Epidemiol 1997, 145:301-308

22. Ott A, Stolk RP, van Harskamp F, Pols HA, Hofman A, Breteler MM: Diabetes mellitus and the risk of dementia: the Rotterdam Study. Neurology 1999, 53:1937-1942

23. Arvanitakis Z, Wilson RS, Bienias JL, Evans DA, Bennett DA: Diabetes mellitus and risk of Alzheimer disease and decline in cognitive function. Arch Neurol 2004, 61:661-666

24. Frisardi V, Solfrizzi V, Seripa D, Capurso C, Santamato A, Sancarlo D, Vendemiale G, Pilotto A, Panza F: Metabolic-cognitive syndrome: a cross-talk between metabolic syndrome and Alzheimer's disease. Ageing Res Rev 2010, 9:399-417

25. Daviglus ML, Plassman BL, Pirzada A, Bell CC, Bowen PE, Burke JR, Connolly ES Jr, Dunbar-Jacob JM, Granieri EC, McGarry K, Patel D, Trevisan M, Williams JW Jr: Risk factors and preventive interventions for Alzheimer disease: state of the science. Arch Neurol 2011, 68:1185-1190

26. Crane PK, Walker R, Hubbard RA, Li G, Nathan DM, Zheng H, Haneuse S, Craft S, Montine TJ, Kahn SE, McCormick W, McCurry SM, Bowen JD, Larson EB: Glucose levels and risk of dementia. N Engl J Med 2013, 369:540-548

27. Kimura N: Diabetes mellitus induces Alzheimer's disease pathology: histopathological evidence from animal models. Int J Mol Sci 2016, 17:503

28. Okabayashi S, Shimozawa N, Yasutomi Y, Yanagisawa K, Kimura N: Diabetes mellitus accelerates $A \beta$ pathology in brain accompanied by enhanced GA $\beta$ generation in nonhuman primates. PLoS One 2015, 10:e117362

29. Honjo S: The Japanese Tsukuba Primate Center for Medical Science (TPC): an outline. J Med Primatol 1985, 14:75-89

30. Honjo S: Guiding principles for animal experiments using nonhuman primates. Primate Rep 1986, 2:111-113 
31. Kanda Y: Investigation of the freely available easy-to-use software "EZR" for medical statistics. Bone Marrow Transplant 2013, 48:452-458

32. Saltiel AR: New perspectives into the molecular pathogenesis and treatment of type 2 diabetes. Cell 2001, 104:517-529

33. Cheng Z, Tseng Y, White MF: Insulin signaling meets mitochondria in metabolism. Trends Endocrinol Metab 2010, 21:589-598

34. Vieira OV, Bucci C, Harrison RE, Trimble WS, Lanzetti L, Gruenberg J, Schreiber AD, Stahl PD, Grinstein S: Modulation of Rab5 and Rab7 recruitment to phagosomes by phosphatidylinositol 3kinase. Mol Cell Biol 2003, 23:2501-2514

35. Houle S, Marceau F: Wortmannin alters the intracellular trafficking of the bradykinin B2 receptor: role of phosphoinositide 3-kinase and Rab5. Biochem J 2003, 375:151-158

36. Kalia M, Kumari S, Chadda R, Hill MM, Parton RG, Mayor S: Arf6independent GPI-anchored protein-enriched early endosomal compartments fuse with sorting endosomes via a Rab5/phosphatidylinositol-3'-kinase-dependent machinery. Mol Biol Cell 2006, 17: 3689-3704

37. Kimura N, Okabayashi S, Ono F: Dynein dysfunction disrupts intracellular vesicle trafficking bidirectionally and perturbs synaptic vesicle docking via endocytic disturbances a potential mechanism underlying age-dependent impairment of cognitive function. Am J Pathol 2012, 180:550-561

38. Kimura N, Samura E, Suzuki K, Okabayashi S, Shimozawa N, Yasutomi Y: Dynein dysfunction reproduces age-dependent retromer deficiency: concomitant disruption of retrograde trafficking is required for alteration in $\beta$-amyloid precursor protein metabolism. Am J Pathol 2016, 186:1952-1966

39. de Duve C, de Barsy T, Poole B, Trouet A, Tulkens P, Van Hoof F: Commentary: lysosomotropic agents. Biochem Pharmacol 1974, 23: $2495-2531$

40. Nixon RA, Cataldo AM, Mathews PM: The endosomal-lysosomal system of neurons in Alzheimer's disease pathogenesis: a review. Neurochem Res 2000, 25:1161-1172

41. Ueda N, Tomita T, Yanagisawa K, Kimura N: Retromer and Rab2dependent trafficking mediate PS1 degradation by proteasomes in endocytic disturbance. J Neurochem 2016, 137:647-658

42. Brunzell JD, Ayyobi AF: Dyslipidemia in the metabolic syndrome and type 2 diabetes mellitus. Am J Med 2003, 115 Suppl 8A:24S-28S

43. Adeli K, Lewis GF: Intestinal lipoprotein overproduction in insulinresistant states. Curr Opin Lipidol 2008, 19:221-228

44. Ginsberg HN, MacCallum PR: The obesity, metabolic syndrome, and type 2 diabetes mellitus pandemic, part I: increased cardiovascular disease risk and the importance of atherogenic dyslipidemia in persons with the metabolic syndrome and type 2 diabetes mellitus. J Cardiometab Syndr 2009, 4:113-119

45. Markgraf DF, Al-Hasani H, Lehr S: Lipidomics: reshaping the analysis and perception of type 2 diabetes. Int J Mol Sci 2016, 17: E1841

46. Di Paolo G, Kim TW: Linking lipids to Alzheimer's disease: cholesterol and beyond. Nat Rev Neurosci 2011, 12:284-296

47. Hua X, Nohturfft A, Goldstein JL, Brown MS: Sterol resistance in CHO cells traced to point mutation in SREBP cleavage-activating protein. Cell 1996, 87:415-426

48. DeBose-Boyd RA, Brown MS, Li WP, Nohturfft A, Goldstein JL, Espenshade PJ: Transport-dependent proteolysis of SREBP: relocation of site-1 protease from Golgi to ER obviates the need for SREBP transport to Golgi. Cell 1999, 99:703-712

49. Dietschy JM, Turley SD: Thematic review series: brain lipids: cholesterol metabolism in the central nervous system during early development and in the mature animal. J Lipid Res 2004, 45: $1375-1397$

50. Suzuki R, Lee K, Jing E, Biddinger SB, McDonald JG, Montine TJ, Craft S, Kahn CR: Diabetes and insulin in regulation of brain cholesterol metabolism. Cell Metab 2010, 12:567-579

51. LaFerla FM, Green KN, Oddo S: Intracellular amyloid-beta in Alzheimer's disease. Nat Rev Neurosci 2007, 8:499-509
52. Ovsepian SV, O’Leary VB, Zaborszky L, Ntziachristos V, Dolly JO: Synaptic vesicle cycle and amyloid $\beta$ : biting the hand that feeds. Alzheimers Dement 2018, 14:502-513

53. Xiao Q, Gil SC, Yan P, Wang Y, Han S, Gonzales E, Perez R, Cirrito JR, Lee JM: Role of phosphatidylinositol clathrin assembly lymphoid-myeloid leukemia (PICALM) in intracellular amyloid precursor protein (APP) processing and amyloid plaque pathogenesis. J Biol Chem 2012, 287:21279-21289

54. Thomas RS, Lelos MJ, Good MA, Kidd EJ: Clathrin-mediated endocytic proteins are upregulated in the cortex of the $\operatorname{Tg} 2576$ mouse model of Alzheimer's disease-like amyloid pathology. Biochem Biophys Res Commun 2011, 415:656-661

55. Bodovitz S, Klein WL: Cholesterol modulates alpha-secretase cleavage of amyloid precursor protein. J Biol Chem 1996, 271: $4436-4440$

56. Simons M1, Keller P, De Strooper B, Beyreuther K, Dotti CG, Simons K: Cholesterol depletion inhibits the generation of betaamyloid in hippocampal neurons. Proc Natl Acad Sci U S A 1998, 95:6460-6464

57. Wahrle S, Das P, Nyborg AC, McLendon C, Shoji M, Kawarabayashi T, Younkin LH, Younkin SG, Golde TE: Cholesteroldependent gamma-secretase activity in buoyant cholesterol-rich membrane microdomains. Neurobiol Dis 2002, 9:11-23

58. Xiong H, Callaghan D, Jones A, Walker DG, Lue LF, Beach TG, Sue LI, Woulfe J, Xu H, Stanimirovic DB, Zhang W: Cholesterol retention in Alzheimer's brain is responsible for high beta- and gamma-secretase activities and Abeta production. Neurobiol Dis 2008, 29:422-437

59. Marquer C, Laine J, Dauphinot L, Hanbouch L, Lemercier-Neuillet C, Pierrot N, Bossers K, Le M, Corlier F, Benstaali C, Saudou F, Thinakaran G, Cartier N, Octave JN, Duyckaerts C, Potier MC: Increasing membrane cholesterol of neurons in culture recapitulates Alzheimer's disease early phenotypes. Mol Neurodegener 2014, 9:60

60. Nixon RA, Mathews PM, Cataldo AM: The neuronal endosomallysosomal system in Alzheimer's disease. J Alzheimers Dis 2001, 3:97-107

61. Nixon RA: Autophagy, amyloidogenesis and Alzheimer disease. J Cell Sci 2007, 120:4081-4091

62. Bjørkøy G, Lamark T, Brech A, Outzen H, Perander M, Overvatn A, Stenmark H, Johansen T: p62/SQSTM1 forms protein aggregates degraded by autophagy and has a protective effect on huntingtininduced cell death. J Cell Biol 2005, 171:603-614

63. Steen E, Terry BM, Rivera EJ, Cannon JL, Neely TR, Tavares R, Xu XJ, Wands JR, de la Monte SM: Impaired insulin and insulinlike growth factor expression and signaling mechanisms in Alzheimer's disease: is this type 3 diabetes? J Alzheimers Dis 2005, 7 $63-80$

64. Moloney AM, Griffin RJ, Timmons S, O'Connor R, Ravid R, O'Neill C: Defects in IGF-1 receptor, insulin receptor and IRS-1/2 in Alzheimer's disease indicate possible resistance to IGF-1 and insulin signalling. Neurobiol Aging 2010, 31:224-243

65. Talbot K, Wang HY, Kazi H, Han LY, Bakshi KP, Stucky A, Fuino RL, Kawaguchi KR, Samoyedny AJ, Wilson RS, Arvanitakis Z, Schneider JA, Wolf BA, Bennett DA, Trojanowski JQ, Arnold SE: Demonstrated brain insulin resistance in Alzheimer's disease patients is associated with IGF-1 resistance, IRS-1 dysregulation, and cognitive decline. J Clin Invest 2012, 122:1316-1338

66. Jin LW, Shie FS, Maezawa I, Vincent I, Bird T: Intracellular accumulation of amyloidogenic fragments of amyloid-beta precursor protein in neurons with Niemann-Pick type $\mathrm{C}$ defects is associated with endosomal abnormalities. Am J Pathol 2004, 164:975-985

67. Lee S, Sato Y, Nixon RA: Lysosomal proteolysis inhibition selectively disrupts axonal transport of degradative organelles and causes an Alzheimer's-like axonal dystrophy. J Neurosci 2011, 31:7817-7830

68. Hui L, Chen X, Geiger JD: Endolysosome involvement in LDL cholesterol-induced Alzheimer's disease-like pathology in primary cultured neurons. Life Sci 2012, 91:1159-1168 
69. Malnar M, Kosicek M, Lisica A, Posavec M, Krolo A, Njavro J, Omerbasic D, Tahirovic S, Hecimovic S: Cholesterol-depletion corrects APP and BACE1 misstrafficking in NPC1-deficient cells. Biochim Biophys Acta 2012, 1822:1270-1283

70. Barbero-Camps E, Roca-Agujetas V, Bartolessis I, de Dios C, Fernández-Checa JC, Marí M, Morales A, Hartmann T, Colell A: Cholesterol impairs autophagy-mediated clearance of amyloid beta while promoting its secretion. Autophagy 2018, 14:1129-1154

71. Cutler RG, Kelly J, Storie K, Pedersen WA, Tammara A, Hatanpaa K, Troncoso JC, Mattson MP: Involvement of oxidative stress-induced abnormalities in ceramide and cholesterol metabolism in brain aging and Alzheimer's disease. Proc Natl Acad Sci U S A 2004, 101:2070-2075

72. Lazar AN, Bich C, Panchal M, Desbenoit N, Petit VW, Touboul D, Dauphinot L, Marquer C, Laprévote O, Brunelle A, Duyckaerts C: Time-of-flight secondary ion mass spectrometry (TOF-SIMS) imaging reveals cholesterol overload in the cerebral cortex of Alzheimer disease patients. Acta Neuropathol 2013, 125:133-144

73. Demeester N, Castro G, Desrumaux C, De Geitere C, Fruchart JC, Santens P, Mulleners E, Engelborghs S, De Deyn PP, Vandekerckhove J, Rosseneu M, Labeur C: Characterization and functional studies of lipoproteins, lipid transfer proteins, and lecithin: cholesterol acyltransferase in CSF of normal individuals and patients with Alzheimer's disease. J Lipid Res 2000, 41:963-974

74. Pfrieger FW: Cholesterol homeostasis and function in neurons of the central nervous system. Cell Mol Life Sci 2003, 60:1158-1171

75. Corder EH, Saunders AM, Strittmatter WJ, Schmechel DE, Gaskell PC, Small GW, Roses AD, Haines JL, Pericak-Vance MA: Gene dose of apolipoprotein E type 4 allele and the risk of Alzheimer's disease in late onset families. Science 1993, 261:921-923

76. Strittmatter WJ, Saunders AM, Schmechel D, Pericak-Vance M, Enghild J, Salvesen GS, Roses AD: Apolipoprotein E: high-avidity binding to betaamyloid and increased frequency of type 4 allele in late-onset familial Alzheimer disease. Proc Natl Acad Sci U S A 1993, 90:1977-1981

77. Holtzman DM, Herz J, Bu G: Apolipoprotein E and apolipoprotein E receptors: normal biology and roles in Alzheimer disease. Cold Spring Harb Perspect Med 2012, 2:a006312

78. Shinohara M, Kanekiyo T, Yang L, Linthicum D, Shinohara M, Fu Y, Price L, Frisch-Daiello JL, Han X, Fryer JD, Bu G: ApoE2 eases cognitive decline during aging: clinical and preclinical evaluations. Ann Neurol 2016, 79:758-774

79. Shepardson NE, Shankar GM, Selkoe DJ: Cholesterol level and statin use in Alzheimer disease, I: review of epidemiological and preclinical studies. Arch Neurol 2011, 68:1239-1244 